[DOI: 10.24214/jecet.A.9.3.42938.]

Jaurnal of Enviranmental Science, Computer Science and Engineering \& Technology

An International Peer Review E-3 Journal of Sciences and Technology

Available online at www.jecet.org

Section A: Environmental Science

Research Article

\title{
Changes of acute toxicity of E2 before and after chlorination
}

\author{
${ }^{1,2}$ Achille Lutumba Suika and ${ }^{2}$ Zhang liqiu \\ ${ }^{1,}$ College of Soil and Water Conservation and Combating Desertification, Beijing Forestry \\ University, 35 Qinghua East Road 10083, Haidian District, Beijing-China. \\ ${ }^{1,2}$ Beijing Key Lab for Source Control Technology of Water Pollution, College of Environmental \\ Science and Engineering, Beijing Forestry UniversityBeijing 100083, China
}

Received:12May 2020; Revised:03June 2020; Accepted:11June 2020

\begin{abstract}
In recent years, envrionmental hormone in drinking water has been constantly detected. These pollutants will produce various disinfection by-products during chlorine disinfection process in drinking water, which are likely to have greater biological toxicity than the precursors and impose a threat to human health. Therefore, it warrants detailed studies on the biological toxicity of such pollutants in water before and after chlorination.17ß-estradiol (E2) as frequently exposed to drinking water, the variation of acute toxicity of drinking water containing E2 before and after chlorination were investigated. The acute toxicity was studied by the algae toxicity test. The results of acute toxicity test showed that under the single exposure condition of different concentrations of E2 $(0,2,4,8,16 \mathrm{mg} / \mathrm{L})$, the growth inhibition rate of Chlorella vulgaris showed obvious dosage effect. with an increase in the exposure concentration of E2, Chlorella vulgaris growth inhibition rate increased correspondingly. With a high chlorine dosage (E2 and chlorine molar ratio of 1:2 and 1:5), the growth inhibition rate of water samples to Chlorella vulgaris was higher than that before chlorination, but under the condition of low chlorine dosage (E2 and chlorine molar ratio of 4:1 and 1:1), the growth inhibition rate of water samples to Chlorella vulgaris was lower than that before chlorination. These results indicated that a low chlorine dosage could reduce the acute toxicity of water quality.
\end{abstract}

Keywords: $17-\beta e s t r a d i o l$, chlorine disinfection, acute toxicity 


\section{INTRODUCTION}

In recent years, with the development of high-sensitivity analytical technologies, a number of PhACs (Pharmaceuticals )have been detected in drinking water in some countries and regions, including China ${ }^{[1-13]}$. Residual PhACs in aquatic environments originate from a variety of sources. The direct or indirect release of medications, WWTP effluents, sludge reuse and landfill, livestock, aquaculture and various human activities can lead PhACs to enter the aquatic environment ${ }^{[14]}$

The frequently detected PhACs sparked widespread concerns of scholars across the world. Due to the complexity of PhACs species, low levels, stable, and poorly biodegradable, their ecological risks and potential toxicities are still unclear. Conventional wastewater treatment processes are not able tore move PhACs completely and may even turn them into more toxic substances. Effluents from wastewater treatment plants (WWTPs) can introduce trace PhACs to the aquatic environment, and eventually to drinking water sources, causing health threats to human beings. Studies have shown that WWTP effluents may contain 17ß-estradiol (E2), which concentration could reach64 $\mathrm{ng} / \mathrm{L}$. Despite the low level of these estrogens, their endocrine disrupting effects and negative ecological effects cannot be ignored ${ }^{[15]}$.

The persistence of PhACs in the environment has certain toxicological effects on aquatic plants, animals and humans. However, the concentration of pharmaceuticals in water environment is very low and their eco toxicity effects on aquatic organisms and human health cannot be found in a short time, therefore, the exposure of pharmaceuticals has been ignored. In recent years, with the improvement of public safety awareness and the improvement of detection level, researchers in many countries have carried out relevant research work on the eco toxicity of PhACs.

Chlorine, as a conventional chemical disinfectant used in drinking water disinfection, has been the main substance for disinfection of drinking water over the years because of its low price and convenience for wide application. Chlorine had a strong bactericidal ability, destroying the enzyme system of algae and other microbial cells. Chlorine and sodium hypochlorite solution are commonly used for drinking water chlorination disinfection technology. The reaction principle is shown as Eq.(1-1) and Eq. (1-2).

$\mathrm{Cl}_{2}+\mathrm{H}_{2} \mathrm{O} \rightarrow \mathrm{HOCl}+\mathrm{Cl}^{-}+\mathrm{H}^{+}$

$\mathrm{HOCl} \rightarrow \mathrm{OCl}^{-}+\mathrm{H}^{+}$

Studies have shown that chlorination effectively remove sulfonamides, chloropyridine, sulfamethazine, sulfadoxine, sulfadimidine, sulfathiazole, trimethoprim, carbadox and other antibiotics,with the removal rate of $50 \%$ to $90 \%$. Further studies have shown that natural organic matters (NOMs) in water affect the removal and disinfection of PhACs, and some of the degradation products detected during chlorination were even more toxic than their parent compounds $^{[16]}$.

\section{MATERIALS AND METHODS OF ALGAE TOXICITY TEST}

2.1. Experimental Instruments and Reagent Materials: The main experimental instruments in algae toxicity experiments were shown in Table1: 
Table1: Experimental instruments and equipment's

\begin{tabular}{|l|l|}
\hline \multicolumn{1}{|c|}{ Instrument } & \multicolumn{1}{|c|}{ Model } \\
\hline Intelligent artificial climate box & RXZ-380B \\
\hline Ultra-low temperature refrigerator & Thermo-ULT1386 $^{-1}$ \\
\hline UV spectrophotometer & Evolution ${ }^{\text {TM }} 300$ \\
\hline Visible spectrophotometer & 722S \\
\hline Water bath thermostat oscillator & THZ-82A \\
\hline Electronic analytical balance & Sartorius BT125D \\
\hline Ultrasonic cell crusher & JY92- II N \\
\hline Inverted fluorescence microscope & XSP-63XD \\
\hline Portable pressure sterilization pot & YX-24HDD \\
\hline
\end{tabular}

The main reagents used in the algae toxicity test were shown in Table2:

Table2: List of reagents and materials

\begin{tabular}{|c|c|c|c|}
\hline Materials and Reagents & $\begin{array}{l}\text { Purit } \\
\mathbf{y}\end{array}$ & Use & Available from \\
\hline Estradiol & $>99 \%$ & $\begin{array}{l}\text { Research } \\
\text { object }\end{array}$ & Sigma-Aldrich Company in USA \\
\hline $\mathrm{NaClO}$ & $\sim 13 \%$ & $\begin{array}{l}\text { Chlorine } \\
\text { disinfectant }\end{array}$ & Sigma-Aldrich Company in USA \\
\hline $\begin{array}{l}\text { Coomassie brilliant blue protein } \\
\text { reagent kit }\end{array}$ & - & $\begin{array}{l}\text { Determination } \\
\text { of soluble protein }\end{array}$ & $\begin{array}{l}\text { Nanjing Jiangcheng Bioengineering } \\
\text { Institute }\end{array}$ \\
\hline $\begin{array}{l}\text { Superoxide dismutase (SOD) } \\
\text { kit }\end{array}$ & - & $\begin{array}{l}\text { Determination } \\
\text { of SOD activity }\end{array}$ & $\begin{array}{l}\text { Nanjing Jiangcheng Bioengineering } \\
\text { Institute }\end{array}$ \\
\hline Catalase (CAT) kit & - & $\begin{array}{l}\text { Determination } \\
\text { of CAT activity }\end{array}$ & $\begin{array}{l}\text { Nanjing Jiangcheng Bioengineering } \\
\text { Institute }\end{array}$ \\
\hline Malondialdehyde (MDA) kit & - & $\begin{array}{l}\text { Determination } \\
\text { of MDA content }\end{array}$ & $\begin{array}{l}\text { Nanjing Jiangcheng Bioengineering } \\
\text { Institute }\end{array}$ \\
\hline
\end{tabular}

2.2 Culture of Chlorella vulgaris: Chlorella vulgaris were provided by Chinese research academy of environmental sciences and the initial concentration was $3.6 \times 10^{4}$ cell $/ \mathrm{ml}$. They were inoculated into fresh sterile M11 media ( $\mathrm{pH}=8.10 \pm 0.05$ ). The ratio of M11 medium was shown in Table3. When the algae reached the logarithmic growth phase, they were transferred to fresh culture media2-3 times until they were vigorous and in the logarithmic growth period that meet the requirements for algae test.. The light intensity for the cultivation was controlled at $4000 \mathrm{~lx}$, the temperature was maintained at $23 \pm 1{ }^{\circ} \mathrm{C}$, and the light and dark cycle was $12 \mathrm{~h}$. In order to avoid Chlorella vulgaris growing with adherence and reduce the experimental error, it is recommended to 
shake conical flasks at least three times a day and change the placing position randomly so that the Chlorella vulgaris cells were evenly suspended and receiving light. All glassware used in the experiment should be soaked with dilute acid overnight and rinsed with tap water, then cleaned with ultrasonic, and finally washed with deionizer water(DI) $(18 \mathrm{M} \Omega \cdot \mathrm{cm})$ three times before drying. Glassware and culture medium were autoclaved $\left(121^{\circ} \mathrm{C}\right)$ for $30 \mathrm{~min}$ before use.

Table 3: Composition in medium of M11

\begin{tabular}{|c|l|c|}
\hline Name & Molecular formula & $\begin{array}{c}\text { Concentration ( } \\
\text { mg/L) }\end{array}$ \\
\hline Sodium nitrate & $\mathrm{NaNO}_{3}$ & 100 \\
\hline $\begin{array}{c}\text { Magnesium sulfate } \\
\text { heptahydrate }\end{array}$ & $\mathrm{MgSO}_{4} \cdot 7 \mathrm{H}_{2} \mathrm{O}$ & 75 \\
\hline Calcium chloride & $\mathrm{CaCl}_{2} \cdot 2 \mathrm{H}_{2} \mathrm{O}$ & 20 \\
\hline Sodium carbonate & $\mathrm{NaCO}_{3}$ & 6 \\
\hline Ferric citrate & $\mathrm{C}_{6} \mathrm{H}_{5} \mathrm{O}_{7} \mathrm{Fe} \cdot \mathrm{XH}_{2} \mathrm{O}$ & 10 \\
\hline Dipotassium phosphate & $\mathrm{K}_{2} \mathrm{HPO}_{4}$ & 1 \\
\hline Disodium edetate & $\mathrm{Na}_{2} \mathrm{EDTA}_{2} 2 \mathrm{H}_{2} \mathrm{O}$ & 20 \\
\hline
\end{tabular}

\subsection{Acute Toxicity Test of Chlorella vulgaris}

2.3.1 Preparation of test solutions and chlorination: According to the results of the preliminary study, the concentration gradient of E2 was set to $0,2,4,8$ and $16 \mathrm{mg} / \mathrm{L}$. The specific method was as follows: $0.01,0.02,0.040 .08 \mathrm{~g}$ E2 were dissolved in $1 \mathrm{~mL}$ methanol and then added with DI water to $50 \mathrm{~mL}$ to get the mass concentration of $0.2,0.4,0.8,1.6 \mathrm{mg} / \mathrm{L}$ of the stock solution, preserved in $\operatorname{dark}\left(4^{\circ} \mathrm{C}\right)$.It has been proved that methanol had no effect on the oxidation of the $\operatorname{drug}^{[17] 7}$ and the bio toxicity of Chlorella vulgaris ${ }^{[18}$.

In the chlorination group, the molar ratio of $\mathrm{E} 2$ to $\mathrm{Cl}_{2}$ was $4: 1,1: 1,1: 2$, and 1:5, respectively. Drugs were chlorinated in a brown bottle $\left(24 \pm 0.5^{\circ} \mathrm{C}\right.$ for $\left.24 \mathrm{~h}\right)$. The excess chlorine was then purged with nitrogen to ensure that the concentration of residual chlorine was below the detection limit $(<0.002$ $\mathrm{mg} / \mathrm{L}$ ) (Federation and Association, 2005). At the same time, the blank control group (no drug and no chlorine) and the drug control group (drug and no chlorine) were set upin triplicates.

2.3.2 Determination of biomass: $3 \mathrm{~mL}$ Chlorella vulgaris solution was taken and then ODwavelength scanning was performed by using an ultraviolet-visible spectrophotometer. The scanning range is $350-800 \mathrm{~nm}$ and the wavelength interval is $5 \mathrm{~nm}$. The OD values were recorded at different wavelengths, and the maximum absorption peak wavelength is $680 \mathrm{~nm}$. The Chlorella vulgaris solution was then diluted to a certain concentration, and its OD was measured at $680 \mathrm{~nm}$. In addition, microscopic counting was performed by the method of platelet count ${ }^{[19] 17}$.Plotted the regression curve with OD as the abscissa, algal cell concentration as the ordinate, which was shown in Fig. 1.It was cleart hat the OD and algal cell concentration showed a good linear correlation $\left(\mathrm{R}^{2}\right.$ $=0.996$ ), which could be expressedby $\mathrm{y}=26.617 \mathrm{x}+1.2744$. 


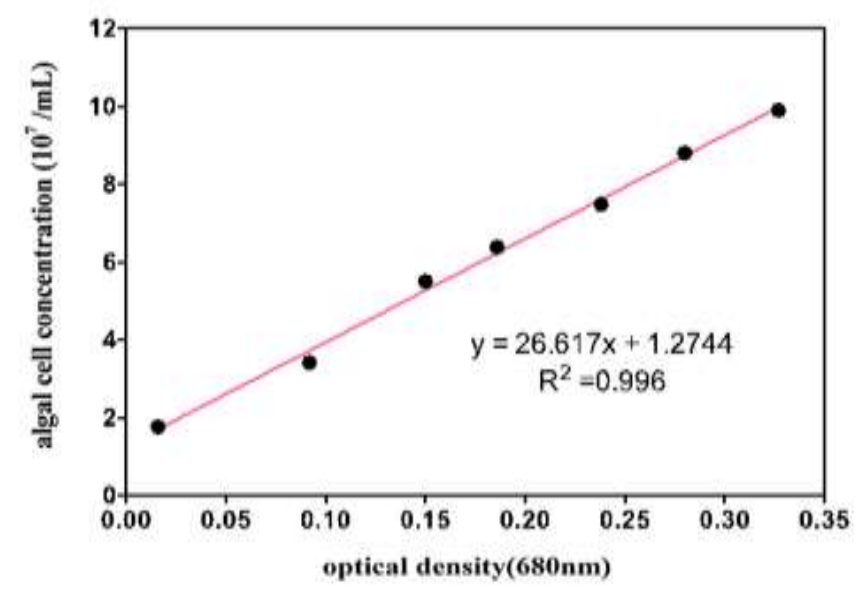

Fig. 1: The correlation between algal cell concentration and optical density of Chlorella vulgaris.

2.3.3 Growth inhibition test of Chlorella vulgaris: According to the Chemical-Algae Growth Inhibition Test (GB/T 21805-2008), the test solutions were prepared by mixing the Chlorella vulgaristhat were in the logarithmic growth phase with the experimental solution, the blank group and the control group. The experimental period was $72 \mathrm{~h}$, and the OD of each test solution was measured every $24 \mathrm{~h}$ after the experiment started. The specific growth rates of Chlorella vulgaris, which means the growth of the daily biomass of Chlorella vulgaris during the test period, and the rate of growth inhibition based on specific growth rates, were shown in equations (2-1) and (2-2), respectively:

$$
\mu=\frac{\ln X_{n}-\ln X_{0}}{t}(2-1)
$$

where $\mu$ is the specific growth rate $\left(\mathrm{d}^{-1}\right), \mathrm{X}_{\mathrm{n}}$ is the algal cell concentration on day $\mathrm{n}, \mathrm{X}_{0}$ is the algal cell concentration in the initial test solution and $\mathrm{t}$ is the time of culture. $I=\frac{\mu_{0}-\mu}{\mu_{0}} \times 100 \%(2-2)$

Where I is the growth inhibition rate $(\%), \mu_{0}$ is the average of specific growth rates of each control parallel group and $\mu$ is the specific growth rate of each treatment parallel group.

\section{RESULTS AND DISCUSSION}

3.1. Effects of $\mathbf{E 2}$ on the growth inhibition of Chlorella vulgaris: The growth inhibition of Chlorella vulgaris under different concentrations of E2 was shown in Fig.2.It can be seen that with the increase of E2 concentration, the growth inhibition rate of Chlorella vulgaris significantly increased, especially when it increased to $16 \mathrm{mg} / \mathrm{L}$, the growth inhibition rate of Chlorella vulgaris increased rapidly, reaching the peak at the 2 nd day of culture (greater than $55 \%$ ). As viewed from the time, the growth inhibition rate of Chlorella vulgaris increased first and then decreased, and it was basically the highest at the 2nd day, and then began to decrease gradually. The reason was that with the culture time extending, Chlorella vulgaris was gradually resistant to E2 and had gradually adapted to E2 after 2 days. Ai-jie Jin et a ${ }^{[20]}$.reached similar conclusionsin the study of the growth 
inhibitory effects of Aminopyrine (AMP) on Chlorella vulgaris, that wasthe inhibitory effect of AMP increased with the increase of drug concentration. Moreover, the inhibition of AMP and its DBPSwere the highest in early growth period of Chlorella vulgaris ${ }^{[20]}$.

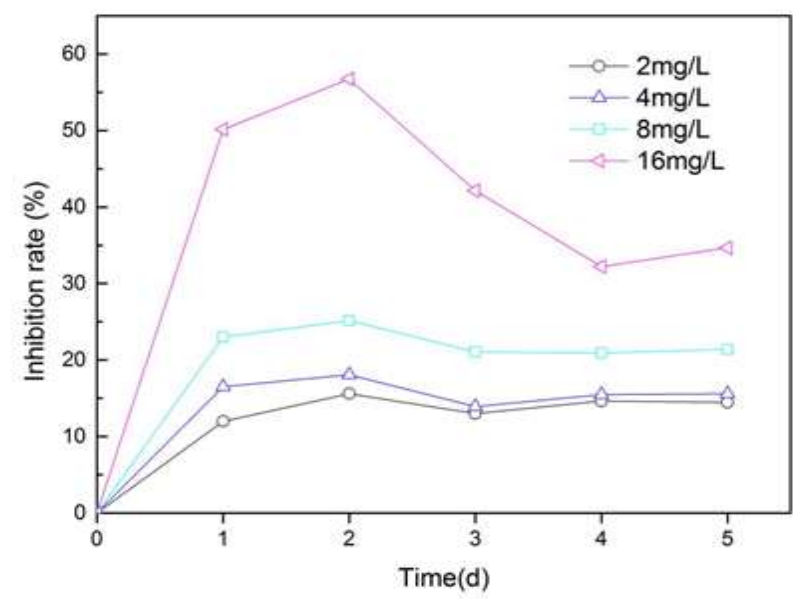

Fig. 2: Effects of different concentrations of E2 on growth inhibition of Chlorella vulgaris

3.2 Effects of $\mathrm{E} 2$ on the growth inhibition rate of Chlorella vulgaris before and after chlorination: The effect on the growth inhibition rate of Chlorella vulgarisinfected by E2 with no chlorine and the molar ratios of E2 to chlorine were 4:1, 1:1, 1:2, 1:5before and after the chlorination was investigated and shown in Fig. 3-1.During the exposure period of 5 days, the growth inhibition rate of Chlorella vulgarisincreased first and then decreased before and after chlorination and finally reached a steady trend. All the maximum inhibition rates appeared onthe 2nd day. On this day, the inhibition rate of Chlorella vulgaris infected by $16 \mathrm{mg} / \mathrm{L}$ E2 with no chlorine was $56.738 \%$ and the inhibition rates of those with the molar ratios of E2 to chlorine were $1: 2$ and $1: 5$ were similar, which were $32.227 \%$ and $32.163 \%$ individually. The results showed that E2 and its DBPs had the strongest inhibitory effect at the initial growth stateof Chlorella vulgaris.
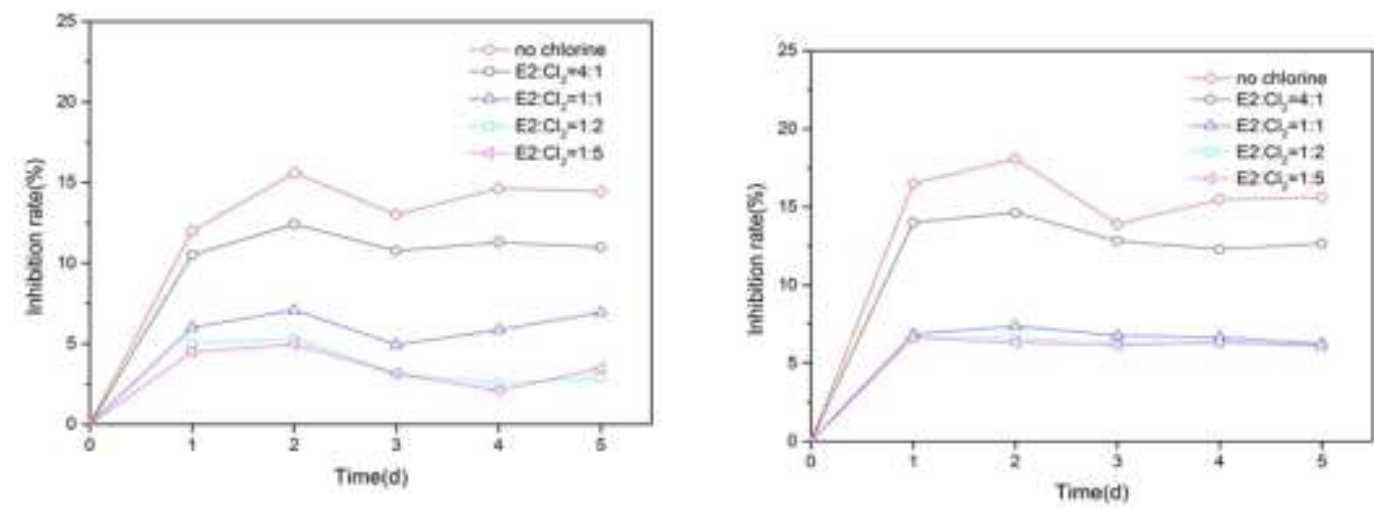

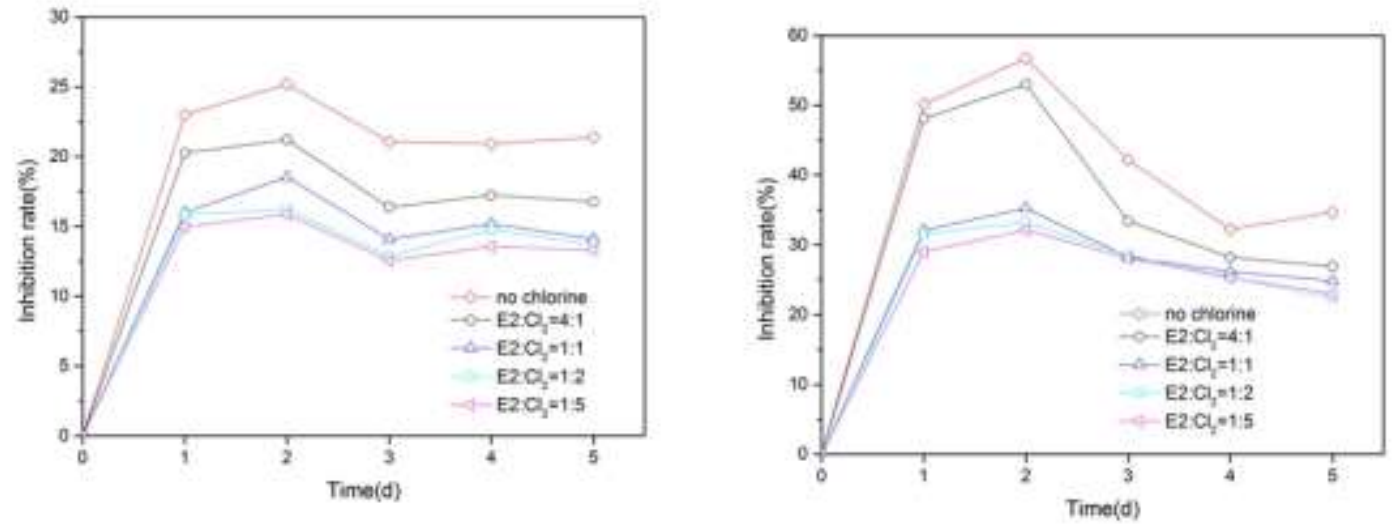

Fig.3-1: Effects of E2with different chlorine doses on the growth inhibition rate of Chlorella vulgaris before and after chlorination.

It can also be seen that at all exposure concentrations of E2, the growth inhibition rate of Chlorella vulgaris after chlorination showed a decreasing trend with the increase of chlorine dosage. When the amount of chlorine was greater (the molar ratios of E2 to chlorine were 1:2 and 1:5), the inhibition rate is basically stable. This indicated that in the process of chlorination disinfection, the acute toxicity of DBPs of E2 is less than E2 itself. In other words, the process of chlorination disinfection decreased the growth inhibition of E2 on Chlorellavulgaris. Chlorinationdisinfection produces seven by-products, including estradiol chloride and two Estradiol chloride.

The effect on the growth inhibition rate of Chlorella vulgaris infected by the same chlorination ratio but different concentrations of E2 $(2,4,8,16 \mathrm{mg} / \mathrm{L})$ before and after the chlorination was investigated and shown in Fig. 3-2. It can be seen that the growth inhibition rate of Chlorella vulgaris increased with the level of DBPs of E2 increasing. When the concentration of E2 increased to $16 \mathrm{mg} / \mathrm{L}$, the growth inhibition rate of Chlorella vulgaris significantly increased, reaching a peak on the 2nd day. When the chlorination ratio was low, the inhibition rate fluctuated obviously, which was close to that by E2 without chlorination. This may be due to the incomplete reaction between E2 and chlorine. When the dose of chlorine increased, the inhibition rate curve is more stable, indicating that the toxicity of DBPs is more moderate under the condition of the high ratio of chlorination.
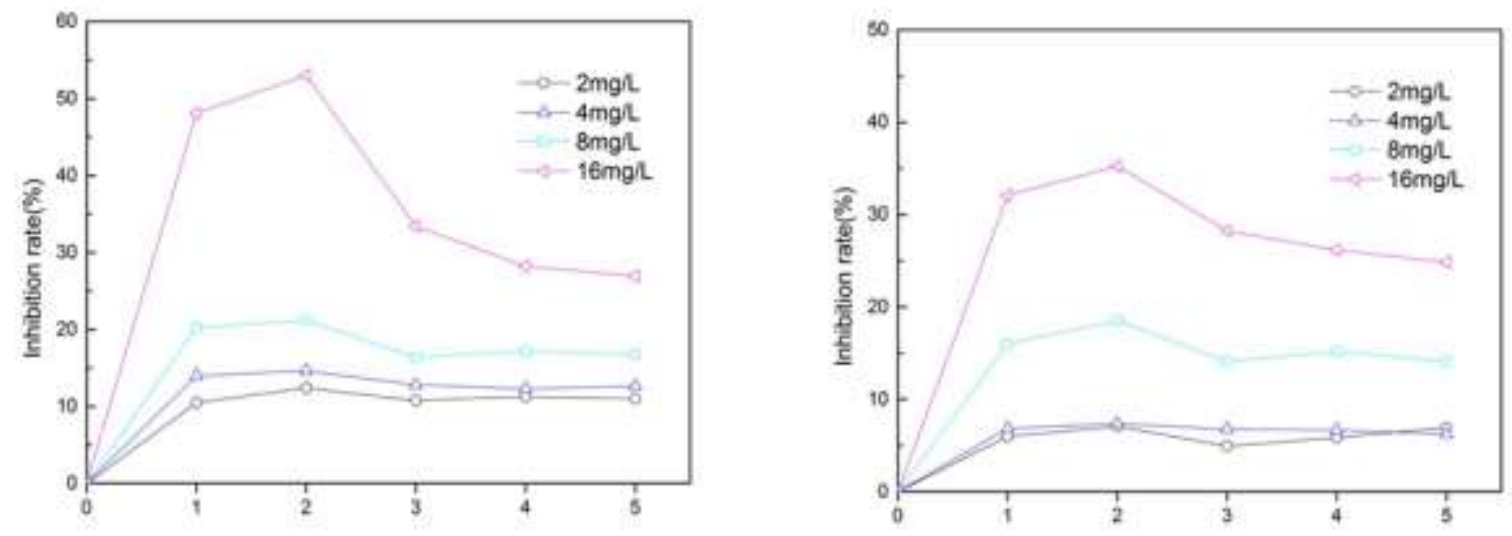

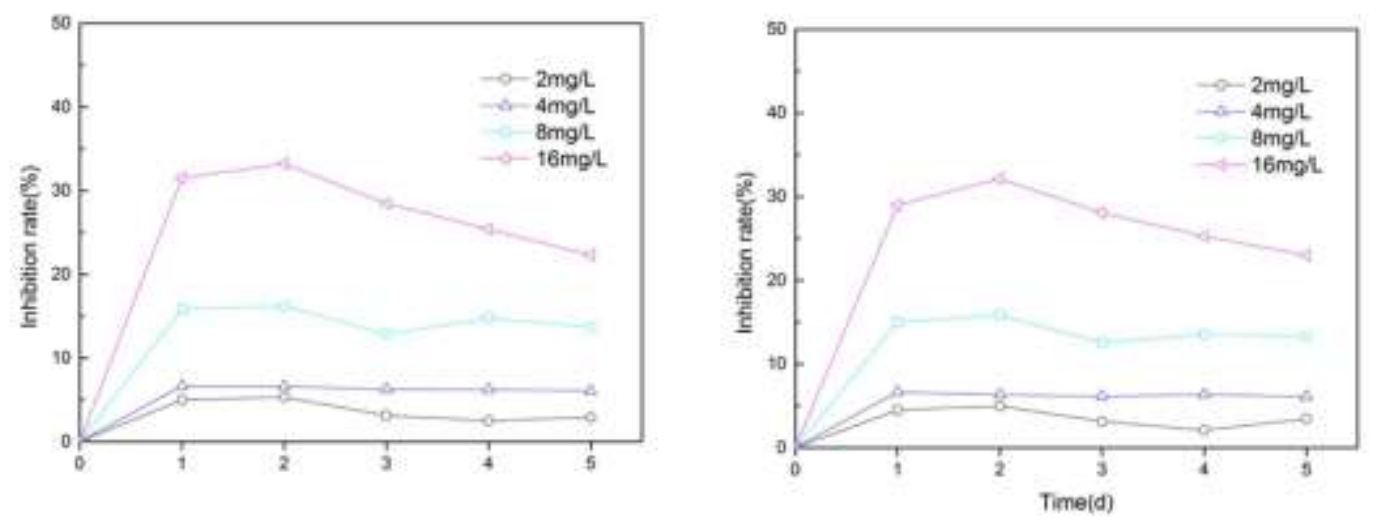

Fig.3-2: Effects of different concentrations of E2 on the growth inhibition rate of Chlorella vulgaris before and after chlorination.

It could be seen from Fig.3-3 that the difference between the inhibition rates of low concentrations of E2 (2 mg/L and $4 \mathrm{mg} / \mathrm{L})$ and high chlorination ratios (1:2 and 1:5), and inhibition rates of E2 with no chlorine remained at about $10 \%$. Compared with low concentrations of E2 $(2 \mathrm{mg} / \mathrm{L}$ and 4 $\mathrm{mg} / \mathrm{L}$ ), the difference between the inhibition rates of the high concentration of E2 and high chlorination ratios $(16 \mathrm{mg} / \mathrm{L}, 1: 2$ and 1:5) and the high concentration of E2 and low chlorination ratios $(16 \mathrm{mg} / \mathrm{L}, 4: 1$ and $1: 1)$ were from $21.15 \%$ to $24.625 \%$ on the $2 \mathrm{nd}$ day, indicating that chlorination can effectively reduce the biological toxicity of the high concentration of E2 (16 $\mathrm{mg} / \mathrm{L})$.

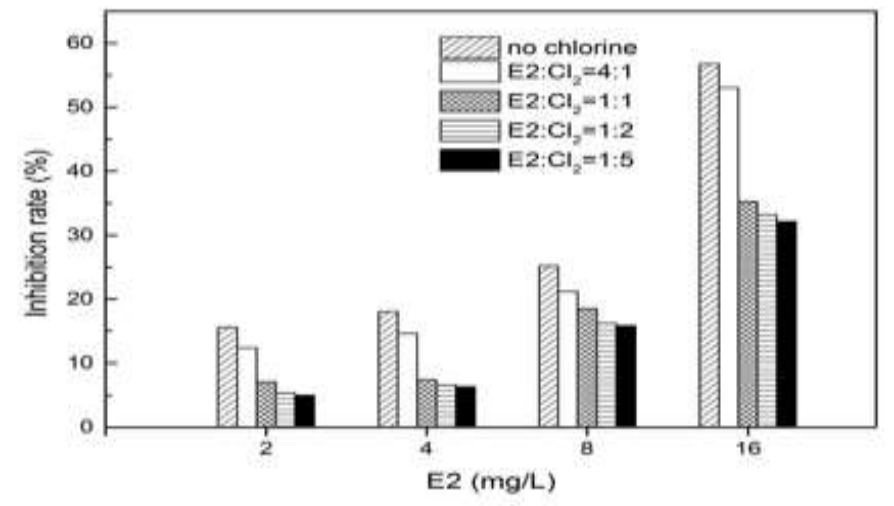

Fig.3-3: Effects of different conditions of E2 on the growth inhibition rate of Chlorella vulgaris before and after chlorination on the 2 nd day.

\section{CONCLUSION}

Changes of acute toxicity of E2 in the process of chlorination and the influencing factors were studied. Chlorella vulgaris were cultured for $120 \mathrm{~h}$ with different initial concentrations of E2 and different dose of chlorine. The relationship between the optical density and the quantity of Chlorella vulgaris was used to reflect the acute toxicity of E2.The main conclusions were as follows:

1. Under the condition of different concentrations of E2 with no chlorine, the growth inhibition rate of Chlorella vulgaris increased with the concentration of E2 increasing, 
and reached a maximum on the 2nd day. When the E2 exposure concentration increased to $16 \mathrm{mg} / \mathrm{L}$, the growth inhibition rate could be over $55 \%$.

2. After chlorination, the growth inhibition rate of Chlorella vulgaris infected by E2 showed a decreasing trend with an increase in chlorine dosage, indicating that the chlorination treatment reduced the inhibitory effect of E2 on the growth of Chlorella vulgaris.

3. Chlorination for high concentrations of E2 can be more effective in reducing its biological toxicity.

Before chlorination, with an increase in E2 concentration, the growth inhibition rate of Chlorella vulgaris increased obviously, and reached the peak onthe 2nd day. When the concentration of E2 was increased to $16 \mathrm{mg} / \mathrm{L}$, the growth inhibition rate of Chlorella vulgaris reached more than $55 \%$.After chlorination, the inhibition rate of E2 on Chlorella vulgaris showed a decreasing trend with an increase in chlorine dosage, indicating that the process of chlorination alleviated the growth inhibition of Chlorella vulgaris by E2.

\section{REFERENCES}

1. S.K.Behera,H.W.Kim, J.E.Oh, H.S.Park, Occurrence and removal of antibiotics,hormones and several other pharmaceuticals in wastewater treatment plants of the largest industrial city of Korea[J].Science of the Total Environment,2011,409,4351-4360.

2. J.M.Brausch, G.M.Rand, A review of personal care products in the aquatic environment: environmental concentrations and toxicity [J]. Chemosphere, 2011, 82, 1518-1532.

3. T.Heberer,K. Reddersen,A.Mechlinski,From municipal sewage to drinking water: fate and removal of pharmaceutical residues in the aquatic environment in urban areas[J].Water Science \& Technology,2002, 46,81-88.

4. T.Jones-Lepp, Chemical markers of human waste contamination: analysis of urobilin and pharmaceuticals in source waters[J].Journal of Environmental Monitoring, 2006,8,472-478.

5. K.E.Lee, L.B.Barber,E.T.Furlong, J.D.Cahill, D.W.Kolpin, M.T.Meyer, S.D.Zaugg, Presence and distribution of organic wastewater compounds in wastewater, surface,ground, and drinking waters,Minnesota,2000-02[J].US Geological Survey Scientific Investigations Report,2004,5138,47.

6. A.M.Peck, K.C.Hornbuckle, Synthetic musk fragrances in Lake Michigan [J]. Environmental science \& technology, 2004, 38,367-372.

7. X.Peng, Q.Huang,K.Zhang,Y. Yu , Z.Wang,C.Wang, Distribution,behavior and fate of azole antifungals during mechanical, biological and chemical treatments in sewage treatment plants in China[J].Science of the Total Environment,2012,426,311-317.

8. K.Quednow, W.Püttmann,Organophosphates and synthetic musk fragrances in freshwater streams in Hessen/Germany[J].CLEAN-Soil,Air,Water,200836,70-77.

9. K.Reddersen, T.Heberer, U.Dünnbier, Identification and significance of phenazone drugs and their metabolites in ground-and drinking water[J].Chemosphere,2002,49,539-544.

10. T.A.Ternes, Occurrence of drugs in German sewage treatment plants and rivers[J].Water research,1998,32,3245-3260. 
11. T.A.Ternes, M. Meisenheimer, D. McDowell, F. Sacher, H.J. Brauch,B. Haist-Gulde ,G. Preuss,U.Wilme, N.Zulei-Seibert, Removal of pharmaceuticals during drinking water treatment[J].Environmental science \& technology,2002,36,3855-3863.

12. T. Wintgens, F.Salehi, R.Hochstrat, T.Melin, Emerging contaminants and treatment options in water recycling for indirect potable use[J].Water Science and Technology,2008,57,99108.

13. S.Zhang, Q. Zhang, S. Darisaw,O. Ehie,G.Wang, Simultaneous quantification of polycyclic aromatic hydrocarbons (PAHs), polychlorinated biphenyls (PCBs), and pharmaceuticals and personal care products (PPCPs) in Mississippi river water,in New Orleans, Louisiana,USA[J].Chemosphere,2007,66,1057-1069.

14. Zhou Xuefei, Zhang Yalei, Dai Chaomeng. Study on the mechanism of removing drugs and personal care products (PPCPs) in urban sewage treatment system $[\mathrm{J}]$.Environmental Protection Nursing Science, 2009, 35, 15-17.

15. J.L. Liu, M.H. Wong, Pharmaceuticals and personal care products (PPCPs): a review on environmental contamination in China. Environment international,2013, 59, 208-224.

16. C.Adams, Y.Wang, K. Loftin, M.Meyer, Removal of antibiotics from surface and distilled water in conventional water treatment processes[J].Journal of environmentalengineering, 2002,128,253-260.

17. M.C.Dodd, A.D.Shah, U. Von Gunten, C.H.Huang , Interactions of fluoroquinolone antibacterial agents with aqueous chlorine:reaction kinetics, mechanisms, and transformation pathways[J]. Environmental science \& technology,2005,39,7065-7076.

18. E.D.De Melo, A.H.Mounteer, L.H.De Souza Leão, R.C.B.Bahia, I.M.F.Campos , Toxicity identification evaluation of cosmetics industry wastewater[J].Journal of hazardous materials,2013,244,329-334.

19. Shen Pingping, Wang Zhaohui.Determination of microalgal biomass by optical density method [J] .Journal of Jinan University: Natural Science and Medicine Edition, 2001, 22,115-119.

20. Ai-jie Jin, Li Feng, Liqiu Zhang, Yong-ze Liu.Changes of the toxic potential of drinking water containing aminopyrine before and after chlorine disinfection as determined by the algal toxicity assay and the SOS/umu assay. International Biodeterioration \& Biodegradation, 2016.

\section{* Corresponding Author:Achille Lutumba Suika}

College of Soil and Water Conservation and Combating Desertification, Beijing ForestryUniversity, 35 Qinghua East Road 10083, Haidian District, Beijing-China.

Date of publication on line 11.06.2020 